\title{
Animalidad e inteligibilidad de lo sensible: Un hombre de Oriana Falacci.
}

\author{
Animality and sensitive intelligibility: A man by Oriana Falacci. \\ Rolando Javier Bonato \\ Departamento de Letras. Facultad de Humanidades. Universidad Nacional del Comahue \\ (ARGENTINA) \\ CE: rolandobonato@gmail.com / ID ORCID: 0000-0002-1683-9949
}

DOI: $\underline{10.32870 / \text { sincronia.axxiv.n77.21a20 }}$

Esta obra está bajo una Licencia Creative Commons Atribución-NoComercial 4.0 Internacional $\mathrm{BY} \cdot \mathrm{NC}$

Recibido: 30/09/2019

Revisado: $14 / 10 / 2019$

Aprobado: 05/11/2019

\section{RESUMEN}

A lo largo de la Modernidad, los movimientos masivos y las muchedumbres han sido tema de análisis y debates no sólo del poder estatal y científico sino también en los grupos ilustrados e intelectuales que han considerado las potencialidades y los riesgos de desestabilización del status quo por parte de las irrupciones plebeyas.

En esta presentación, me interesa trabajar primeramente con las reflexiones llevadas a cabo en el siglo XX que toman como eje, rasgos de los movimientos masivos que asumen características o inscripciones asociadas al mundo animal. Una de los pensadores que han tenido en cuenta esta dimensión es Elías Canetti en su trabajo Masa y poder (1960). Este pensador observa que uno de los rasgos que expresan un movimiento masivo es el ritmo de movimiento en ascenso, tal como sucede con las manadas en busca de las presas.

En un segundo momento, me interesa plantear la articulación que se da entre la animalidad de los movimientos masivos con aquellos rasgos presentes en las expresiones artísticas literarias: ruptura con el orden simbólico de la lengua, problematización de los binarismos cultura/naturaleza, 
instinto/razón. Estos presupuestos hipotéticos serán articulados con la novela Un hombre de Oriana Falacci.

Palabras clave: Animal. Literatura. Masa. Humanidad.

\section{ABSTRACT}

Along the Modernity, the massive movements and crowd have been analyzed for the estate power, lawyers and social scientists. All of them reflected about its potentialities and risks of threat the status quo.

In this text, I am working the animal traits massive movements. So, Crowd and power by Elias Canetti will be the theoretical main reference. This intellectual says that the upward rhythm is the first characteristic of the herd when its hunt. The Elias Canetti perspective talks for opposite to Gustave Le Bon and Sigmund Freud.

Then, I'll link the animal and massive movement expressions whit literature artistic expressions. Its break the binarisms: culture/nature, instinct/reason. The focus will be in the novel $A$ man by Oriana Falacci.

Keywords: Animal. Literature. Crowd. Humanity.

La masa de acoso se da tanto entre los animales como en el hombre, y es verosímil que su formación entre hombres se haya vuelto a nutrir siempre de modelos animales [...]. La masa de acoso se constituye teniendo como finalidad la consecución de una meta con toda rapidez [...]. La víctima es la meta en sí misma. (Canetti, 1960, p.43)

\section{Animalidad, masa y Estado modernos}

La masa como acontecimiento cultural e histórico nace junto con la Modernidad y el incipiente Estado moderno, así lo expresa Elías Canetti en Masa y Poder (1960). A lo largo del devenir cultural se la ha impugnado desde el poder por asumir rasgos o comportamientos identificados con la animalidad y el 
quebranto de los ideales liberales precisamente porque la intempestividad de las muchedumbres, en tanto experiencia colectiva y psicosocial, problematiza el autocentramiento del sujeto y la relación que este debería entablar con el mundo en términos de fetichización y mercantilización. Masa y animalidad han configurado una particular sinergia desde donde se le ha opuesto otros términos decisivos para el desarrollo moderno: civilización / razón (Canetti 1960). Su movimiento y representación asumen rasgos identificados por fuera de la esfera racional, en un espacio intersticio que va de la mera pulsión irracional e iracunda de la multitud hacia la disputa política por su reconocimiento en la inserción en el orden del logos. Se podría indicar que la Revolución francesa fue el suceso que concedió al movimiento de la muchedumbre la conciencia histórica del cambio radical. Ahora bien, estas dos entidades, masa / animal y Estado pueden articularse en tanto dinámica intrínseca del devenir moderno por cuanto toda acción de control, fijación o disciplinamiento de la Ley precipitó una réplica plebeya. En algunos casos, estas réplicas condujeron a una acción que fueron equivalentes con rasgos de un orden apartado de la racionalidad.

Reflexionar sobre la naturaleza de esta expresión inusitada del estallido, a la luz de algunos referentes letrados o intelectuales modernos, propiciará un análisis crítico de las condiciones a partir de las cuales se identificó como binarismo irreductible, la díada humanidad / animalidad. En un segundo momento, se extrapolarán estas reflexiones a uno de los territorios en que la literatura evidencia, dentro del horizonte de la ficción, el vínculo conflictivo y dialéctico entre masa animal / Ley de una manera que reformula las estrategias hegemónicas de verdad y realidad.

El Estado moderno contiene en su haber un orden que incluye un sistema legal, económico y político de relaciones y regulaciones sociales de acuerdo a la tradición liberal que se nutre del pensamiento de Jean Jacques Rousseau y John Locke, para quienes la propiedad privada, la ley y el principio de justicia se encuentran dentro del sistema estatal; por fuera de este no existe orden posible. Profundamente constituido junto con la clase burguesa y el liberalismo, el Estado participó, precisamente por esta articulación, en el afianzamiento del sistema capitalista y la expansión colonialista en sus diversas etapas y potencias imperiales. Si bien los orígenes del Estado moderno se sitúan en los albores del Renacimiento europeo, será con las consecuencias de la Revolución Francesa 
en que adquirirá una visión auto consciente más nítida. La eficacia en la administración del Estado estuvo sostenida por una compleja maquinaria burocrático / institucional que tuvo la responsabilidad de garantizar su funcionamiento práctico; un entramado capaz de generar estrategias de autolegitimidad y regulación propias de una esfera autónoma.

El mismo Hobbes define en una argumentación liberal la injusticia como el incumplimiento de un pacto pre establecido. Aquello que sale de lo que la Ley prescribe como injusto no está en el orden de la justicia y, por lo tanto, susceptible de ser corregido a través del castigo. El derecho y la ley articulan una polaridad que anuncian la libertad y la realización humana junto a la promesa de orden social e individual. El efecto performativo de la Ley establece la obediencia o, en su forma más extrema, el terror para lograr la concreción de sus tácticas. El castigo que redime a la sociedad de la violencia causada por quien delinque se sostiene en un principio de daño y violencia: "Una pena es un daño infligido por la autoridad pública (...) como una transgresión de la ley, con el fin de que la voluntad de los hombres pueda quedar, de ese modo, mejor dispuesta para la obediencia." (Hobbes 1940: 254). Como consecuencia, la Modernidad definió una escisión insalvable entre orden sensible del inteligible. De un lado la emocionalidad, lo irracional e iracundo, y, del otro, la civilización, el logos, lo político.

Vinculado con el terror, para la mitología griega el dios Dionisos es el mayor exponente de los antecedentes terroristas premodernos, ya que representa tanto el vino, la festividad, el exceso, la generación de vida, como la deidad que encarna la sangre, la venganza y el castigo hacia quien se aparta de su despótica ley. De hecho, es el dios que puede encender las más despiadadas acciones de venganza para quienes se atrevan a desafiar sus reglas. Concluye Eagleton sobre esta deidad:

Es atroz, voraz y monolíticamente hostil ante las diferencias; y ello es en gran medida inseparable de sus rasgos más seductores (...) lo que contribuye a la dicha también contribuye a la carnicería. Disolver el yo en la naturaleza mediante el éxtasis, como hace Dionisio, es caer presa de una violencia atroz. Si la felicidad perfecta no es posible con el yo, tampoco lo es sin él. (Eagleton, 2008, p.15) 
De manera que el Estado moderno es, en esta lectura dionisíaca y terrorista, conformador de un espacio de la violencia para el sostenimiento de sus proclamas progresistas y su expresado interés hegemónico, conjuntamente con una red de prácticas tendientes a sostener una dádiva capaz de interceptar el deseo y el horizonte de espera para quien plácidamente se entregue a sus prerrogativas. Se pone de manifiesto, así, un aspecto de la secularización de la cultura política moderna que sigue, en sus sentidos, a Walter Benjamin para quien, tal como afirma en su paradigmático texto El capitalismo como religión, la culpa y la deuda delinean la configuración de la relación del capitalismo y su inscripción religiosa en el que no se redime de la culpa.

\section{Masa iracunda y animal}

El primer rasgo característico de toda masa es el ritmo de sus movimientos a través del caminar o el correr. Elías Canetti reconoce en este aspecto la vinculación animal de la masa cuando afirma: "El ritmo es originalmente un ritmo de los pies (...). La escritura más temprana que aprendió a leer fue la de las huellas (...). Expresaban todo esto en un determinado estado de excitación común que designo como masa rítmica o palpitante." (Canetti, 1981, p.26). Dentro de los tipos de expresiones masivas que caracteriza Canetti aparecen las masas de acoso y fuga que son las más próximas al comportamiento y emulación animal tanto por sus estrategias de ataque como de defensa:

La de acoso y la masa de fuga son las dos más antiguas. Se dan tanto entre los animales como en el hombre, y es verosímil que su formación entre hombres se haya vuelto a nutrir siempre de modelos animales (...). La masa de acoso se constituye teniendo como finalidad la consecución de una meta con toda rapidez. (Canetti, 1981, p.43).

Asimismo, la categoría de masa presupone una experiencia colectiva que implica una toma de conciencia en un sentido más puntual que las relativas equivalencias con la multitud o el pueblo. Es Andrea Cavalletti (2013) el que lleva esta idea al indicar que la masa despierta del sueño del orden capitalista. La masa se expresa en una revuelta, una protesta, una concentración o en una revolución y, en todos los casos, hay una suspensión del tiempo instaurado por el poder. En una revuelta se deja 
de estar solo para compartir en una comunión de individuos la ruptura de lo instituido y allí emerge, nuevamente, el estar juntos comunitariamente. En una experiencia exitosa de la masa se produce la distensión de los efectos subjetivos y performativos del poder. Según las reflexiones de Andrea Cavalletti, al incendiarse un archivo, los perseguidos por la justicia son conscientes de la liberación y purificación que el fuego produce al deslindarlos de las ataduras de la Ley.

El terror a la invasión y la eventual destrucción de la masa de su entorno social llevó a una experiencia particular en una aldea francesa, mientras se producía la revuelta de París en 1789. En efecto, una aldea entera fue auto evacuada por terror a que los insurgentes los acribillaran. A la mañana siguiente y tras ocultarse en el bosque, los aldeanos fueron conscientes de que nada podría haber sucedido. Dice Cavalletti en relación a esta acontecimiento:

Hasta que el alba revela que el peligro era sólo imaginario, un mal sueño con los ojos abiertos: ya pertenece al pasado, y los hombres pueden volver tranquilos a sus burgos. Pero precisamente entonces explota el delirio colectivo. Y así los indefensos fugitivos se convierten en cazadores implacables, la parálisis del pánico muta en exaltación homicida; y el peligro fantástico da lugar a persecuciones incluso demasiado reales. (Cavalletti, 2013, p.27).

La masa tiene otro rasgo a considerar y es su condición de descarga. Ésta se articula con una tradición que se remonta, en principio, a Gustave Le Bon (1975) y Elías Canetti (1977). La masa cuando descarga a través de una serie de acciones contundentes es proclive a la acción compulsiva e incluso violenta promovida por una injusticia o lo que la masa entienda como tal. Este impulso, muchas veces identificado con la idea de injusticia no está en sintonía con la representación que de ésta tenga el Estado. Con la descarga, según Elías Canetti se materializa el sentido de una masa: “El acontecimiento más importante (...) es la descarga (...). La integra realmente. Se trata del instante en el que todos los que pertenecen a ella quedan despojados de sus diferencias y se sienten como iguales." (Canetti, 1977, p.12).

Se puede señalar que, dentro de la clasificación propuesta por Canetti, se destaca la masa abierta ya que lleva implícito un deseo de crecimiento, de ahí que su existencia esté en lugares 
abiertos y públicos. La masa comienza con su desintegración cuando se llega al punto máximo de crecimiento. En oposición a la masa abierta aparece la cerrada que renuncia a la potencia de crecimiento fijando sus límites y densidad como los estadios de fútbol o recitales; el espacio físico la determina y enmarca. Pierde posibilidad de crecimiento ininterrumpido pero gana en perduración mientras el espectáculo permanezca. Estabilidad y reiteración son sus rasgos más destacados. También se gana en una mayor posibilidad de orden y control además de estar más atravesado por la mercantilización de la experiencia masiva. La descarga, tal como se indicó, es el rasgo más importante de una masa. El anhelo por crecer y producir la descarga fortalece su unidad. Canetti particulariza la masa dentro del escenario moderno y la vincula con el proceso de secularización de la cultura:

A partir de la Revolución francesa estos estallidos han ido adquiriendo una forma que percibimos como moderna. Quizás porque la masa se ha liberado en tal medida de las religiones tradicionales, nos resulta más fácil, a partir de entonces, verla desnuda, es decir, biológicamente, sin las inyecciones de sentido y metas trascendentes con que antes se dejaba vacunar. (Canetti, 1981, p. 17).

Ante lo expuesto, la hipótesis que se presenta reconoce la dialéctica producida entre masa y Estado, díada integrada por términos que son mutuamente influyentes. El doble efecto de esta articulación supone por un lado, que las masas pueden ser persuadidas y no sólo reprimidas por el Estado, a través de distintos modos de negociaciones de la política; y por otro lado, el Estado aminora la disciplina social a partir de las aglomeraciones sociales pacíficas o violentas. La noción de masa, en su vínculo con la animalidad, presupone la experiencia de un yo colectivo bajo los presupuestos de movimiento, ritmo e ingesta sacrificial como condición que posibilita el crecimiento y la descarga. En el epígrafe con el que se inició el artículo se vinculan las masas de acoso y de ataque en su necesidad por ingesta y descarga. Se advierte que el sentido de su acción se orienta hacia la captura de una presa como instinto de supervivencia y gregarismo. La animalidad es el resto que discurre tanto en el Estado de terror como en la inscripción flamígera de la masa. 


\section{Masa y estética en el horizonte de la inteligibilidad y lo inminente}

La relación que la masa tiene con la estética recupera el vínculo perdido en la modernidad entre cuerpo y aesthesis. Terry Eagleton (2006) recuerda el sentido etimológico de la estética para rescatar una construcción poética regida por una dimensión sensible de los sentidos, capaz de afectar al sujeto que se apropia. Este alcance intercepta al cuerpo más que al logos y lo vincula al arte en la esfera de la comunidad, reconociendo alrededor de la experiencia lo indecible, lo que escapa o problematiza al logocentrismo, aquello que extrañifica lo instituido y reconoce en la paradoja, la deriva de la experiencia humana en el tiempo.

Junto con la sensibilidad por la percepción corporal, la estética se rige con una dinámica próxima a la masa en el sentido que busca romper la automatización perceptual. Se entiende esta idea de ruptura perceptual en el sentido formulado por los formalistas rusos en el contexto de las vanguardias históricas de principios de siglo XX. Es decir, se parte de la distinción de una lengua automatizada que imposibilita una visión crítica de la realidad. Al extrañificar la lengua, la realidad cobra una dimensión perceptual diferencial. Es así que, tal como lo explicaron Víctor Shklovsky, Roman Jakobson y Boris Eichembaum entre otros, al extrañificar la materialidad con la que opera la función poética, la realidad se ve transformada en la mirada del sujeto que la contempla. Pero allí donde el arte provoca, emerge la condición de posibilidad para que el sentido, el logos o la ideología dominante puedan ser vistos a través de una lectura atenta. Es una nueva forma de problematización de lo sensible ya que éste se presenta como un horizonte de lo inteligible al dar cuenta de la comprensión de la experiencia humana en el tiempo. ¿Qué hace la estética con la masa / animal en tanto recurso formal? Pone en funcionamiento, precisamente, la relación Estado / compulsa social al pensar el reparto de lo sensible en el sentido descripto por Jacques Ranciere (2011). Para este intelectual, el arte intercepta la política no en la tradición liberal moderna sino más bien, al representar lo que la política excluye en nombre del demos. Jacques Ranciere recuerda que la idea de logos no solo es pensamiento sino cómputo y, la política moderna se ha encargado de invisibilizar aquellos grupos y espacios que se encuentran fuera de toda representación política pero que son, al 
mismo tiempo, nombrados en nombre de la idea de pueblo. El reparto de lo sensible formula la idea de un arte que acerca una visión en la que se da cuenta de estos malos cómputos en la política. En esta apuesta se procura interceptar la Ley que instituye coercitivamente identidades en un sujeto que busca la experiencia del devenir y lo abierto (Agamben, 2006).

\section{El gemido animal en El hombre de Oriana Falacci}

El hombre (1983) de Oriana Falacci da cuenta en su principio constructivo de la relación masa / animalidad en su intersección conflictiva con el Estado. Esta relación de términos lleva a dar cuenta de la exaltación de una figura histórica, la del dirigente griego Alekos Panagoulis, en su vínculo conflictivo con la política y la dictadura de los años 70 en Grecia. La novela plantea precisamente la denuncia a la violencia de Estado y la arbitrariedad manifiesta de la justicia y la ley. En la ficción sobresalen dos imágenes asociadas a la animalidad: una es durante el ceremonial del velatorio y otra en la sepultura del protagonista.

Este relato se detiene centralmente en el velatorio del protagonista tras el crimen de Estado hacia él; la historia se encuentra narrada a través de la voz de su compañera, Oriana Falacci. El enorme colectivo que participa del movimiento de masa en el velatorio expresa el rugido animal de una herida infringida por le ley. La nueva novela histórica, provisoriamente ${ }^{1}$ utilizaremos ese horizonte genérico en la que se inscribe la obra. La autora implicada (Ricoeur; 2008) reconstruye la trayectoria política del dirigente y su ingreso a la vida política formal de su país dentro del contexto totalitario de la Dictadura de los coroneles en la década de 1970. Hay dos momentos en la totalidad del texto que atraviesa la imagen de la animalidad: una es la voz de Alekos cuando ve a su verdugo y gime un aullido anterior a un ataque: "Aparecieron zumbando cuatro motociclistas y una caminata policial (...).

\footnotetext{
${ }^{1}$ Se entiende por nueva novela histórica a las reflexiones formuladas por Noé Jitrik (2001) en relación a la evolución de la novela histórica acontecida en la segunda mitad del siglo XX. Este género literario se inscribe para problematizar las condiciones de representación del pasado histórico, la ambivalencia de los modos de pensar la identidad del sujeto y centralmente, a revisar desde una dimensión particularmente crítica el poder en su vínculo con la hegemonía.
} 
Apenas tuve tiempo de ver un rostro redondo y grisáceo, un bigotito oscuro, y tu boca se deformó en un aullido feroz." (Falacci, 1983, p.160).

Para esta presentación, me detendré en el episodio del funeral de Alekos tras su asesinato ya que encontramos una representación del público expectante del ceremonial funerario de la masa articulada a través de un animal, el pulpo. Lo que se destaca es una estructura en clímax organizada en tres momentos decisivos. En primer lugar, aparece la irrupción intempestiva del pulpo ingresando con el fin de devorar el cuerpo de Panagoulis. Luego, aparece la ingesta del cuerpo para, finalmente, desplazarse hacia afuera del recinto con el féretro como centro de la imagen. La exhibición del cadáver del dirigente político hegemoniza el relato. El proceso de clímax crea la figura de la onomatopeya de la multitud, y el cadáver ostenta ser la cabeza visible del pulpo.

El bestiario permite a la novela marcar el pulso de descarga del pueblo. La idea de vestuario con la que se trabaja en este artículo presupone la figuración de un animal del que se ordena todo un acontecimiento psicosocial. Este vínculo de bestiario y psiquismo se lo puede anclar a la narrativa de Julio Cortázar: "El pulpo irrumpió en el interior espumajeando, arrojando por delante sus chorros de lava. Se elevaron aullidos de miedo, pedidos de ayuda, y el cráter se estrechó en un remolino (...). Alguien gritó ‘iAtrás bestias, ¿quieren comerlo?!'”. (Falacci, 1984, p.14). El ingreso a la sala de velatorio se inicia con el movimiento animal de la masa pulpo. Esto significa el ingreso intempestivo de la muchedumbre que, en la mirada configurante de la voz narradora, es representado en términos de un animal. La selección léxica alrededor del agua - "chorros", "espumajeando"- y el pánico suscitado por el ingreso de la bestia señalan el inicio del clímax. La imprecación con la alusión de la ingesta puntúa la tensión orientada al clímax: "Pero ya no era posible controlar a la bestia que enloqueció (...). Como si ya no bastara rugir y ahora quisiera devorarte, arqueó el cuerpo entero (...). Y oponer una barrera a las garras que intentaban reabrirla." (Falacci, 1984, p.14). La intempestividad inicial en el ingreso a la sala se ve ahora precipitada a la necesidad de la ingesta del cuerpo público.

El retiro del cadáver hacia la sepultura crea el tercer momento de una masa que habiendo digerido el cuerpo lo instituye como su cabecera: "El furgón aparece como una manchita confusa, sofocada en el vórtice de una masa compacta, el ojo del ciclón, la cabeza del pulpo." (Falacci, 1984, 
p.15). La llegada al cementerio se destaca por el fin del aumento y descarga de la expresión masiva como condición necesaria de la masa que, aquí, es definida compacta: "El pulpo ya no rugía ni se sobresaltaba, ya no empujaba. Sin embargo, allí estaba. Con una maniobra de tenazas, algunos de sus tentáculos habían precedido al furgón, y decenas de millares hormigueaban en el cementerio y sus alrededores." (Falacci, 1984, p.15). La masa compacta es, para Canetti, el máximo punto de expansión ya que concentra todo el impulso y energía necesarios para colisionar el orden al cual se enfrenta. Terminada esta máxima tensión se produce la colisión de fuerzas que es, al mismo tiempo, coincidente con el procedimiento formal del clímax dentro del género literario de la novela.

Sobre ti cayeron los primeros terrones (...) el pulpo los oyó. Y se estremeció con un seco escalofrío, casi una descarga eléctrica, se rompió el silencio desgarrado en un tumulto apocalíptico. Y unos gritaban no-está-muerto, Alekos-no-está-muerto, y otros gritaban palabras incomprensibles (...). Se renovó el rugido; incesante, ensordecedor, obsesivo, disipando todos los restantes sonidos, escondiendo la enorme mentira: zi, zi,zi. Vive, vive, vive. (Falacci, 1984, p.16).

Cuando la masa animal llega al cementerio regurgita el intento de una nueva descarga antes que el ataúd caiga a la sepultura. Es el punto en que el llanto y los gritos desenfrenados por la desaparición del líder imposibilitan la fuerza de choque del yo colectivo. Cada uno se encuentra absorto en su dolor, resignando toda sinergia colectiva:

\section{Cierre}

El procedimiento del clímax que se indicó y que modula la tensión del relato ejemplifica uno de los puntos en que el arte contemporáneo, a través de la literatura, capta la ficción, la pasión y la política humanas. Lo hace desde la escisión de lo comunitario y la razón. Es decir, los colectivos humanos se encuentran desde una distancia crítica con el orden simbólico y especialmente el Estado. La representación de la animalidad crea un registro, una pulsión de la memoria apelando a otra del orden de los cuerpos, del tejido social y la lengua. Rugidos, sonidos guturales, ingestas simbólicas 
grafican la exploración de sujetos modernos por la apertura que les permita, en palabras de Giorgio Agamben, abrirse al encuentro con el otro por fuera de las prerrogativas en que el poder binario y logocéntrico quebranta la pulsión vital y la nuda vida.

\section{Referencias:}

Agamben, G. (2006). Lo abierto. El hombre y el animal, Buenos Aires: Adriana Hidalgo.

Benjamin, Walter. 2008. El capitalismo como religión disponible en http://catigaras.blogspot.com/2008/05/el-capitalismo-como-religin-walter.html

Canetti, E. (1981). Masa y poder, Barcelona: Muchnik.

Cavalletti, A. (2013). Clase. El despertar de la multitud, Buenos Aires: Adriana Hidalgo.

Eagleton, T. (2008). Terror santo, Barcelona: Debate.

Falacci, O. (1983). Un hombre, Buenos Aires: Javier Vergara.

Hobbes, T. (1940). Leviatán o la materia, forma y poder de una república eclesiástica y civil, México:

FCE.

Jitrik, Noé. 2001. Historia e imaginación literaria. Las posibilidades de un género. Buenos Aires: Biblós.

Le Bon, G. (1975). Psicología de las masas, Buenos Aires: Albatros.

Ranciere, J. (2011). El malestar de la estética, Buenos Aires: Capital Intelectual.

Ricoeur, P. (2008). Tiempo y narración III, Buenos Aires: Paidós.

Rousseau, J. (1999). El contrato social, Buenos Aires: Ciudad argentina.

Sloterdijk, P. (2002). El desprecio de las masas. Ensayo sobre las luchas culturales de la sociedad moderna, Madrid: Pre Textos. 